Arq. Bras. Med. Vet. Zootec., v.68, n.5, p.1390-1394, 2016

\title{
Comunicação
}

[Communication]

\section{Produção de embriões em ovinos Morada Nova e Somalis Brasileira}

\author{
[Embryo production in Morada Nova and Somalis Brasileira ewes] \\ O.O. Brasil ${ }^{1}$, N.H. Moreira ${ }^{1}$, T.A.S.N. Silva ${ }^{1}$, B.D.M. Silva ${ }^{2}$, N.V. Nascimento ${ }^{2}$, \\ O. Facó ${ }^{3}$, A.F. Ramos ${ }^{2} *$ \\ ${ }^{1}$ Faculdade de Medicina Veterinária e Agronomia - Universidade de Brasília - UnB - Brasília, DF \\ ${ }^{2}$ Embrapa Recursos Genéticos e Biotecnologia - Cenargen - Brasília, DF \\ ${ }^{3}$ Embrapa Caprinos e Ovinos - Sobral, CE
}

Os ovinos deslanados do Nordeste do Brasil apresentam grande importância socioeconômica, em especial, para as populações de média e baixa renda. Entre as raças ovinas adaptadas ao semiárido nordestino, destacam-se a Morada Nova e a Somalis Brasileira, que apresentam grande rusticidade, prolificidade e aptidão para carne e pele. No entanto, a predileção dos criadores por raças comerciais, somada aos cruzamentos indiscriminados, tem provocado a perda de diversidade genética e o risco de extinção de raças localmente adaptadas (Facó et al., 2008; Magalhães et al., 2010).

Diante desse cenário, a aplicação de biotecnologias da reprodução, particularmente, a múltipla ovulação e transferência de embriões (MOTE) é fundamental para os programas de conservação de raças ameaçadas. Contudo, o conhecimento sobre a produção de embriões em ovinos Morada Nova e Somalis Brasileira é bastante limitado. Além disso, a raça pode ter grande influência nos resultados de um programa de MOTE. Este trabalho teve como objetivo avaliar a resposta superovulatória e a produção embrionária de ovelhas Morada Nova e Somalis Brasileira criadas no semiárido nordestino.

O experimento foi aprovado pelo Comitê de Ética Animal (CEUA) do Instituto de Ciências Biológicas da Universidade de Brasília, sob protocolo UnBDOC $\mathrm{n}^{\circ}$. 99694/2012. O ensaio foi realizado na Embrapa Caprinos e Ovinos, em Sobral, CE, situada na região semiárida, a $3^{\circ} 42^{\prime}$ de latitude sul e $40^{\circ} 21^{\prime}$ de longitude oeste, a uma altitude de 83 metros. Foram utilizadas 19 ovelhas Morada Nova e 20 Somalis Brasileira com idades variando entre dois e nove anos e entre dois e seis anos, respectivamente. Todos os animais foram mantidos em pastagem nativa $\mathrm{e}$ com livre acesso à água e a sal mineral.

As fêmeas foram sincronizadas com a inserção de um dispositivo intravaginal contendo $0,3 \mathrm{~g}$ de progesterona (Eazi-Breed CIDR ${ }^{\mathrm{TM}}$ - Controlled Internal Drug Release, Pfizer, Nova Zelândia), no dia zero, substituído no dia sete por um novo dispositivo, que permaneceu até o dia 14. No dia sete, foram administrados $37,5 \mu \mathrm{g}$ de dcloprostenol (Prolise ${ }^{\circledR}$, Tecnopec, ARSA S. R. L., Argentina), por via intramuscular. Para superestimulação, 133mg de FSHp (Folltropin ${ }^{\circledR}$, Tecnopec, Bioniche A. H. C. Inc., Canadá) foram administrados em oito doses decrescentes $(26,6 \mathrm{mg}$ x $2,19,95 \mathrm{mg} \times 2,13,3 \mathrm{mg}$ x 2 e $6,65 \mathrm{mg}$ x 2), aplicadas duas vezes ao dia, iniciando na manhã do dia 12 e encerrando 36 horas após a remoção do CIDR. Uma dose de 200UI de eCG (Novormon5000; Syntex, Buenos Aires, Argentina) foi administrada, em todos os animais, juntamente com a retirada do dispositivo de progesterona. Cinquenta horas após a remoção do CIDR, as fêmeas foram inseminadas por laparoscopia, usando-se sêmen fresco, com $250 \times 10^{6}$ de espermatozoides por dose inseminante.

Recebido em 6 de maio de 2015

Aceito em 15 de novembro de 2015

*Autor para correspondência (corresponding author)

E-mail: alexandre.floriani@embrapa.br 
Em cada raça, quatro carneiros com fertilidade comprovada tiveram o sêmen coletado para uso nas inseminações artificiais (IA). Antes das inseminações, o sêmen foi coletado por meio de vagina artificial (IMV® 100 Technologies, França) e avaliado quanto à concentração, à motilidade massal, à motilidade total e ao vigor espermático. Apenas os ejaculados com concentração $\geq 3$ × $10^{9} \mathrm{sptz} / \mathrm{mL}$, motilidade massal $\geq 3$, motilidade total $\geq 70 \%$ e vigor espermático $\geq 3$ foram utilizados (CBRA, 2013). Após a avaliação, o sêmen foi diluído para se obter uma concentração final de $1 \times 10^{9} \mathrm{sptz} / \mathrm{mL}$, sendo envasado em palhetas francesas de 0,25mL (IMV® Technologies, França). No momento das IA, as ovelhas foram divididas aleatoriamente para receber o sêmen de um dos quatro carneiros.

Cinco dias após a inseminação artificial, as fêmeas foram submetidas à laparoscopia para exame dos ovários. Os corpos lúteos (CL) foram classificados, de acordo com a cor e a condição de desenvolvimento, como normais ou com regressão prematura (RPCL). Ovelhas com RPCL e/ou com menos que três CL foram consideradas não responsivas ao protocolo de superovulação. Os embriões foram recuperados cirurgicamente, sob anestesia geral, por meio da técnica de laparotomia pré-púbica. O útero foi exposto, mediante uma incisão de aproximadamente $8 \mathrm{~cm}$, e cada corno uterino foi lavado com $60 \mathrm{~mL}$ de meio de lavagem (DPBS, Cultilab, Brasil), pré-aquecido a $38^{\circ} \mathrm{C}$ e suplementado com $10 \%$ de soro fetal bovino (FBS, 013/07; Internegócios, Buenos Aires, Argentina). Os embriões coletados foram classificados segundo os critérios morfológicos da Sociedade Internacional de Transferência de Embriões: grau I (excelente ou bom), grau II (regular), grau III (pobre) ou grau IV (degenerado), sendo considerados como viáveis os graus I, II e III.

As análises estatísticas foram realizadas utilizando-se o pacote estatístico SAS (SAS Institute Inc, Cary, NC, 2003). Os parâmetros relativos ao número médio de $\mathrm{CL}$, às estruturas coletadas e aos embriões viáveis foram analisados utilizando-se o teste de MannWhitney. O número de embriões totais foi analisado pelo teste $t$ de Student com correção de Welch. Os dados em porcentagem foram submetidos ao teste exato de Fisher. Os resultados estão apresentados em média \pm desviopadrão ou porcentagem, e as diferenças foram consideradas significativas quando $\mathrm{P}<0,05$.

O percentual de doadoras que responderam ao protocolo de superovulação ( $\geq 3 \mathrm{CL}$ normais) foi de 74\% (14/19) e 50\% (10/20) nas raças Morada Nova e Somalis Brasileira $(\mathrm{P}>0,05)$, respectivamente. A falha na superovulação na raça Morada Nova ocorreu exclusivamente devido à RPCL $(26 \%, 5 / 19)$, enquanto, na raça Somalis Brasileira, além da RPCL $(30 \%, 6 / 20)$, $20 \%$ das doadoras (4/20) apresentaram menos do que três ovulações.

A regressão prematura de corpo lúteo de forma total ou parcial foi verificada em ambas as raças. A RPCL é um problema inerente à superovulação de ovinos, que normalmente resulta em uma baixa recuperação de embriões ou na recuperação de embriões de pior qualidade (Cognie et al., 2003). Portanto, neste estudo, as ovelhas que apresentaram regressão prematura de todos os corpos lúteos ou de parte deles não foram submetidas ao procedimento de coleta de embriões. Os achados relativos à RPCL do presente estudo são semelhantes aos relatados por Lopes Júnior et al. (2006), em que a RPCL total ou parcial ocorreu em 33\% das ovelhas Morada Nova submetidas à superovulação.

Devido à necessidade de se aumentar a eficiência dos protocolos de superovulação, principalmente nas raças de programas de conservação, torna-se essencial a busca por estratégias que reduzam ou impeçam a RPCL. Shabankareh et al. (2012) relataram que a administração de duas doses de 250UI de hCG, uma no momento da remoção do pessário vaginal e a outra $24 \mathrm{~h}$ mais tarde, aumentou o peso e o tamanho do $\mathrm{CL}$ e a concentração de progesterona, estando esses fatores associados à inibição da RPCL em todas as ovelhas superovuladas.

A falha superovulatória ocorre em $20 \%$ das ovelhas submetidas a protocolo de superovulação (Brebion et al., 1992). Neste estudo, um percentual semelhante foi verificado na raça Somalis Brasileira. Embora a falta de resposta superovulatória tenha ocorrido exclusivamente na raça Somalis Brasileira, essa pode ocorrer independentemente da raça. Segundo Lopes Júnior et al. (2006), a ausência de resposta superovulatória também foi registrada em 
ovelhas Morada Nova. Segundo esses autores, aproximadamente $25 \%$ das fêmeas, submetidas a protocolo de superovulação com 200UI de FSHp, não apresentaram resposta superovulatória.

Os resultados referentes à produção de embriões, dos animais com resposta superovulatória, estão expressos na Tab. 1. O tratamento hormonal empregado neste estudo foi eficiente em induzir múltiplas ovulações em ambas as raças. Contudo, o número de corpos lúteos, as estruturas coletadas e o número de embriões das ovelhas Morada Nova foram maiores do que os da Somalis Brasileira $(\mathrm{P}<0,05)$.

Tabela 1. Média \pm desvio-padrão ou porcentagem da resposta superovulatória e produção embrionária de ovelhas Morada Nova e Somalis Brasileira superestimuladas com 133mg de FSHp

\begin{tabular}{lcc}
\hline & Morada Nova & Somalis Brasileira \\
\hline Número de CL & $15,38 \pm 5,24 \mathrm{a}$ & $10,56 \pm 2,83 \mathrm{~b}$ \\
Estruturas coletadas & $11,00 \pm 7,55 \mathrm{a}$ & $3,33 \pm 1,94 \mathrm{~b}$ \\
Total de embriões & $6,79 \pm 5,35 \mathrm{a}$ & $2,90 \pm 2,18 \mathrm{~b}$ \\
Embriões viáveis & $4,86 \pm 7,54$ & $2,0 \pm 2,45$ \\
Taxa de fertilização $(\%)^{1}$ & $109 / 145(75) \mathrm{b}$ & $29 / 30(97) \mathrm{a}$ \\
Taxa de degeneração $(\%)^{2}$ & $41 / 109(38)$ & $9 / 29(31)$ \\
\hline
\end{tabular}

Valores dentro da mesma linha com letras diferentes diferem significativamente $(\mathrm{P}<0,05)$.

${ }^{1}$ (Total de embriões / estruturas coletadas) x 100.

${ }^{2}$ (Total de embriões degenerados / Total de embriões) x 100.

A raça é amplamente reconhecida como um fator de variação da resposta superovulatória e da produção de embriões ovinos (Torres et al., 1987). A raça Morada Nova possui maior prolificidade do que a raça Somalis Brasileira (Facó et al., 2008; Magalhães et al., 2010), o que pode estar envolvido na maior resposta ovariana apresentada nessa raça, após o estímulo com FSHp.

Estudos iniciais com superovulação em ovinos observaram que as raças altamente prolíferas respondem melhor ao estímulo com FSHp exógeno (Bindon et al., 1971; Smith, 1976). As diferenças raciais na resposta superovulatória provavelmente são explicadas por variação no crescimento folicular, entre as raças, em resposta ao FSH exógeno (Ammoun et al., 2006). Tais diferenças podem estar relacionadas com a expressão mais elevada ou com maior sensibilidade dos receptores de FSH no ovário (Driancourt et al., 1986; Dufour et al., 2000).

Os animais das duas raças estudadas, que responderam ao tratamento superovulatório com $133 \mathrm{mg}$ FSHp, apresentaram número de ovulações satisfatório ( $>10$ corpos lúteos). Programas de superovulação realizados com raças localmente adaptadas apresentaram médias de ovulação que variaram entre 7,4 e 13,5 (Cordeiro et al., 2003; Lopes Júnior et al., 2006; Oliveira et al., 2012). Uma boa resposta ovulatória está diretamente relacionada com um maior rendimento embrionário, portanto $\mathrm{o}$ protocolo utilizado neste estudo é uma ferramenta importante para a conservação ex situ de raças localmente adaptadas.

A taxa de fertilização foi elevada nas duas raças, contudo foi utilizado sêmen fresco nas inseminações artificiais, o qual reconhecidamente apresenta maior viabilidade no trato reprodutivo da fêmea e maior poder fecundante. A fertilização na raça Somalis Brasileira foi maior do que na Morada Nova (97\% vs. 75\%, respectivamente; $\mathrm{P}<0,05$ ). Esse resultado não necessariamente ocorreu devido a um fator inerente à fêmea, podendo ter ocorrido devido à utilização de diferentes carneiros em cada raça. Embora os carneiros utilizados tenham fertilidade comprovada e tenham sido adotados critérios mínimos para o uso do sêmen fresco, é possível que a existência de diferenças possa ser atribuída ao sêmen.

Apesar de o total de embriões ter sido numericamente maior na raça Morada Nova, não houve diferença entre o número de embriões viáveis entre as raças $(\mathrm{P}>0,05)$. A elevada taxa de embriões degenerados $(>30 \%)$ contribuiu para a redução no rendimento de embriões viáveis, para ambas as raças. A adoção de protocolos que controlem a dominância folicular e permitam a superestimulação no início da onda de 
crescimento folicular poderia reduzir esse problema. Basicamente existem duas estratégias principais: (1) sincronização da ovulação para iniciar a superovulação na primeira onda folicular (isto é, protocolo do dia zero; Menchaca et al., 2009) e (2) utilização da progesterona associada a uma administração de estradiol para sincronizar a emergência da onda folicular (Barrett et al., 2008). Contudo, essas abordagens, em ovinos, necessitam ser mais bem estudadas.

Devido à variação na resposta superovulatória provocada por fatores genéticos, a adaptação dos protocolos de superovulação para cada raça pode ser importante. O protocolo hormonal deste estudo foi eficiente na superovulação na raça Morada Nova e menos eficiente na raça Somalis Brasileira, sugerindo-se um possível aumento na dose de FSHp no protocolo de superovulação da última raça. Além disso, melhorar a qualidade embrionária e controlar RPCL é indispensável para se realizar um programa de MOTE, com mínimas variações e com o máximo rendimento embrionário, em ambas as raças.

Palavras-chave: superovulação, embrião, FSH, conservação de recursos genéticos

\begin{abstract}
Superovulatory response and embryo yield in 19 Morada Nova and 20 Somalis Brasileira ewes was analyzed. All animals were synchronized with the insertion of an intravaginal device (CIDR®) on Day 0, replaced by a new device on Day 7, which remained in place until Day 14 and superovulated with $133 \mathrm{mg}$ of porcine FSH (pFSH) in decreasing doses at 12h intervals from Day 12 until Day 15 of the treatment, and a single dose of equine chorionic gonadotropin (eCG, 200UI) on Day 14 (i.e., administered in CIDR removal). Fifty hours after $C I D R \circledR$ removal, females were inseminated by laparoscopy. All embryos were recovered by laparotomy 5 days after insemination. Sheep which responded to the superovulation protocol (P>0.05) included $74 \%$ of the Morada Nova ewes and $50 \%$ of the Somalis Brasileira ewes. Morada Nova showed better results $(P<0.05)$ than Somalis Brasileira in number of ovulations $(15.38 \pm$ 5.24 vs. $10.56 \pm 2.83)$, total structures $(11.00 \pm 7.55$ vs. $3.33 \pm 1.94)$ and embryo yields $(6.79 \pm 5.35$ vs. $2.90 \pm 2.18$ ). Despite the high fertilization rate, degenerate embryo rate was high for both breeds, with an overall rate of 39\% (57/145). In conclusion, superovulatory response and embryo yields in Morada Nova ewes were considered sufficient to justify the use of this procedure in genetic resources conservation programs. However, improvements to embryo quality and control of precocious regression of corpus luteum are necessary to produce better results in the MOET program, with minimal variations and maximum embryo yield in Morada Nova and Somalis Brasileira ewes.
\end{abstract}

Keywords: superovulation, embryo, FSH, genetic resources conservation

\section{AGRADECIMENTOS}

À Embrapa Recursos Genéticos e Biotecnologia e à Embrapa Caprinos e Ovinos.

\section{REFERÊNCIAS}

AMMOUN, I.; ENCINAS, T.; VEIGA-LOPEZ, A. et al. Effects of breed on kinetics of ovine FSH and ovarian response in superovulated sheep. Theriogenology, v.66, p.896-905, 2006.

BARRETT， D.M.W.; BARTLEWSKI，P.M.; DUGGAVATHI, R. et al. Synchronization of follicular wave emergence in the seasonally anestrous ewe: The effects of estradiol with or without medroxyprogesterone acetate. Theriogenology, v.69, p.827-836, 2008.
BINDON, B.M.; CHANG, T.S.; TURNER, H.N. Ovarian response to gonadotrophin by Merino ewes selected for fecundity. Austr. J. Agric. Res., v.22, p.809-820, 1971.

BREBION, P.; BARIL, G.; COGNIÉ, Y.; VALLET, J.C. Embryo transfer in sheep and goat. Ann. Zool., v.41, p.331-339, 1992.

COGNIE, Y; BARIL, G.; POULIN, N.; MERMILLOD, P. Current status of embryo technologies in sheep and goat. Theriogenology, v.59, p.171-188, 2003.

CORDEIRO, M.F.; LIMA-VERDE, J.B.; LOPES-JÚNIOR, E.S. et al. Embryo recovery rate in Santa Inês ewes subjected to successive superovulatory treatments with pFSH. Small Rumin. Res., v.49, p.19-23, 2003. 
DRIANCOURT, M.A.; FRY, R.C.; CLARKE, I.J.; CAHILL, L.P. Variations in patterns of follicle development in prolific breeds of sheep. J. Reprod. Fertil., v.78, p.565-575, 1986.

DUFOUR, J.; COGNIE, Y.; MERMILLOD, P. et al. Effects of the Booroola Fec gene on ovarian follicular populations in superovulated Romanov ewes pretreated with a GnRH antagonist. J. Reprod. Fertil., v.118, p.84-95, 2000 .

FACÓ, O.; PAIVA, S.R.; ALVES, L.R.N. et al. Raça Morada Nova: origem, características e perspectivas. Sobral: Embrapa Caprinos, 2008. 43p. (Documentos, 75). LOPES JÚNIOR, E.S.; MAIA E.L.M.M.; PAULA, N.R.O. et al. Effect of age of donor on embryo production in Morada Nova (white variety) ewes participating in a conservation programme in Brazil. Trop. Anim. Health. Prod., v.38, p.555-561, 2006.

MAGALHÃES, A.F.B.; FACÓ, O.; LÔBO, R.N.B.; VILLELA, L.C.V. Raça Somalis Brasileira: origem, características reprodutivas e desenvolvimento ponderal. Sobral: Embrapa Caprinos e Ovinos, 2010. 28p. (Documentos, 99).
MENCHACA, A.; VILARINÕ, M.; PINCZAK, A. et al. Progesterone treatment, FSH plus eCG, GnRH administration, and Day 0 Protocol for MOET programs in sheep. Theriogenology, v.72, p.477-483, 2009.

OLIVEIRA, M.E.F.; CORDEIRO, M.F.; FERREIRA, R.M. et al. Does supplemental LH changes rate and time to ovulation and embryo yield in Santa Ines ewes treated for superovulation with FSH plus eCG? Ciênc. Rural, v.42, p.1077-1082, 2012.

SAS Institute Inc. 2002-2003. Statistical analysis system. Release 9.1. (Software). Cary. USA.

SHABANKAREH, H.K.; SEYEDHASHEMI, S.B.; TORKI, M. et al. Effects of repeated administration of hCG on folicular and luteal characteristics and serum progesterone concentrations in eCG-superovulated Sanjabi ewes. Trop. Anim. Health. Prod., v.44, p.18651871, 2012.

SMITH, J.F. Selection for fertility and response to PMSG in Romney ewes. Proc. N. Z. Soc. Anim. Prod., v.36, p.247-251, 1976.

TORRES, S.; COGNIE, Y.; COLAS, G. Transfer of superovulated sheep embryos obtained with different FSH-P. Theriogenology, v.27, p.407419, 1987. 